\title{
Central Venous Reflux, a Rare Cause of Neurological Manifestations in Hemodialysis Patients: A Case Report and Literature Review
} \author{
Ricardo Reisin, $\mathrm{MD}^{1}$, Pablo Bonardo, $\mathrm{MD}, \mathrm{PhD}^{1}$ \\ ${ }^{1}$ Department of Neurology, Hospital Británico, Buenos Aires, Argentina \\ ${ }^{2}$ Department of Neuroradiology, Hospital Británico, Buenos Aires, Argentina \\ ${ }^{3}$ Department of Interventional Neuroradiology, Hospital Británico, Buenos Aires, Argentina \\ ${ }^{4}$ Department of Nephrology, Hospital Británico, Buenos Aires, Argentina
}

Francisco Caiza-Zambrano, $\mathrm{MD}^{1}$, Carolina Mora Palacio, $\mathrm{MD}^{2}$, Silvia Garbugino, $\mathrm{MD}^{3}$, Fabio Maximiliano Gonzalez, $\mathrm{MD}^{1}$, Marta Bala Biolcati, $\mathrm{MD}^{1}$, Miguel Ángel Saucedo, $\mathrm{MD}^{1}$, Carlos Rugilo, $\mathrm{MD}^{2}$, Mariano Forrester, $\mathrm{MD}^{4}$, Fernando Lombi, $\mathrm{MD}^{4}$, Manuel Fernández Pardal, $\mathrm{MD}^{1}$,

\section{Correspondence to:}

Francisco Caiza-Zambrano, MD Department of Neurology, Hospital Británico, Perdriel 74, C1280 AEB, Buenos Aires, Argentina

Tel: +5491164014389

Fax: +5401143096400

E-mail:fcaiza@hbritanico.com.ar

Received: September 22, 2021 Revised: December 12, 2021 Accepted: December 14, 2021

Key Words: Neurologic manifestations; Renal dialysis; Venous thrombosis; Catheterization, central venous; Vascular access devices

\section{INTRODUCTION}

Central venous disease (CVD) is a serious complication in patients undergoing hemodialysis. It is defined as $>50 \%$ lesion (stenosis or occlusion) in one of the following central veins of the chest: inferior and superior vena cava, brachiocephalic vein $(\mathrm{BCV})$, subclavian vein $(\mathrm{SCV})$, or internal jugular vein (IJV). ${ }^{1}$ Its clinical presentation varies depending on the site of the injury, being more serious the closer it is to the right atrium. It typically manifests with ipsilateral upper limb and facial edema, although it can occur asymptomatically. ${ }^{2}$ Neurological manifestations secondary to CVD are rare., ${ }^{3,4}$ We describe a patient who presented neurological manifestations secondary to central venous reflux due to throm-
Copyright $\odot 2022$ Korean Society of Interventional Neuroradiology This is an Open Access article distributed under the terms of the Creative Commons Attribution Non-Commercial License (http://creativecommons.org/licenses/by-nc/4.0) which permits unrestricted non-commercial use, distribution, and reproduction in any medium, provided the original work is properly cited.

pISSN 2093-9043 eISSN 2233-6273 
botic occlusion of the left BCV. We also performed a systematic review of the literature.

\section{CASE REPORT}

A 51-year-old female presented with a 3-month duration of throbbing headache, of moderate to severe intensity, located in the frontal and retroocular region, without nausea or vomiting. It got worse during dialysis sessions and interfered with her activities of daily living. She also complained of paresthesia, weakness, and abnormal posture of her right hand during headache episodes. Motor symptoms completely resolved after each dialysis session, although the headaches persisted for several hours. No neurological deficit was evidenced on physical examination. Her past medical history includes arterial hypertension and chronic renal failure secondary to focal segmental glomerulosclerosis. Six years ago, she had a deceased donor kidney transplant. Due to the rejection of the transplant, she required hemodialysis through a central venous catheter (CVC) in the right IJV for 7 months. Then, an arteriovenous fistula (AVF) was performed in her left upper limb, and she undergoes hemodialysis through this access until now.

Brain tomography and magnetic resonance imaging did not show acute lesions or signs of intracranial hypertension (optic nerve sheath hydrops, reduced pituitary height, optic disc protrusion, or optic nerve edema). The fundus examination was normal. Magnetic resonance angiography showed high signal intensities of the sigmoid sinus, transverse sinus, and inferior petrosal sinus on the left side due to venous reflux (Fig. 1A-D). Digital subtraction angiography (DSA) ruled out intracranial AVF and identified an incomplete thrombosis (75\%) of the left BCV (Fig. 1E). Delayed venous phase images of DSA showed reverse venous flow in the IJV, sigmoid sinus, and transverse sinus on the left side (Fig. 1F). The patient was not eligible for endovascular treatment due to the difficulty of making a new venous access. The decision was to start anticoagulation with complete resolution of symptoms after 3 months of follow-up.

\section{DISCUSSION}

We described a hemodialysis patient who developed neurological symptoms due to thrombotic occlusion of the left
$\mathrm{BCV}$. The estimated incidence of CVD in patients undergoing hemodialysis ranges from $16 \%$ to $50 \%$. However, the presence of neurological symptoms is rare and nonspecific. ${ }^{5,6}$ In Table $1^{1-20}$, we summarize the cases of neurological manifestations secondary to CVD reported so far. There is no sex prevalence with a mean age of 55.4 years (standard deviation $[S D] \pm 14.1)$. Cardiovascular risk factors were identified in 14 out of 23 patients, with arterial hypertension being the most frequent factor (50\%), and the average time of hemodialysis was 7.1 years $(\mathrm{SD} \pm 3.4)$.

The etiology of CVD is multifactorial. However, CVC placement has been associated with an increased risk of CVD, even after its removal. SCV access has up to 4 times the risk compared to IJV for the development of this pathology. ${ }^{2}$ As well as our patient, CVC placement was described in 6 out of 23 of the reported cases.

In patients without a history of endoluminal devices, hemodynamic abnormalities could explain the development of CVD. Turbulent blood flow due to the presence of AVF would damage the vessel wall, stimulate the development of neointimal hyperplasia, and cause stenosis. Shunts located on the left side are associated with an increased risk of stenosis or thrombosis due to anatomical causes (left BCV is located between the sternum and pulsating aorta, which contributes to stenosis). ${ }^{5,6}$

Among the reported cases, 14 patients (60.9\%) had an AVF, 7 (30.4\%) had an arteriovenous graft, and in 2 cases (8.7\%) the type of shunt was not specified. The mean time from AVF creation to symptoms onset was 4.5 years ( $S D \pm 4.2$ ), and in $65.2 \%$ of patients (15/23), including the present case, the shunt was located in the left upper limb.

Previous studies have found associations between venous reflux and neurological manifestations. Retrograde flow caused by CVD (especially BCV) could cause alteration of the cerebral venous drainage, affect the circulation of the cerebrospinal fluid, and develop intracranial hypertension. ${ }^{6,7}$ Headache attacks in our patient could be explained by this mechanism. On the other hand, intracranial venous congestion decreases cerebral perfusion pressure, which leads to a reduced supply of brain nutrients and potentially causes a hypoxia-like condition and affects neuronal function. ${ }^{8,9}$ This is some of the currently available evidence about the pathophysiology of central venous reflux as a cause of neurological signs and symptoms. Among the patients described, occlusion/thrombosis prevailed over stenosis as a more frequent central lesion, and in the majority of them (87\%) there was 
BCV involvement. The most frequent symptoms and signs were: headache (60.9\%), motor deficits (21.7\%), cranial nerve involvement (17.4\%), and sensory symptoms (4.3\%).

Change of flow direction could also lead to increased cerebral venous pressure, causing ischemia (due to altered cerebral perfusion pressure) or bleeding. ${ }^{1,8,10}$ A brain lesion was present in $30.1 \%$ of reported cases at symptoms onset, which included 3 cerebral infarctions and 3 intraparenchymal hemorrhages. We did not identify brain lesions in our case.
The diagnosis of CVD is based on clinical and imaging findings. A high index of suspicion is necessary for this pathology, where DSA is the gold standard for the diagnosis of this disease due to its greater sensitivity compared to other imaging methods. ${ }^{10}$

Symptoms can be reversible if CVD is treated early. Treatment options include percutaneous transluminal angioplasty (PTA), stenting, and surgery. PTA with a dilatation balloon is the current mainstay of treatment and should be performed
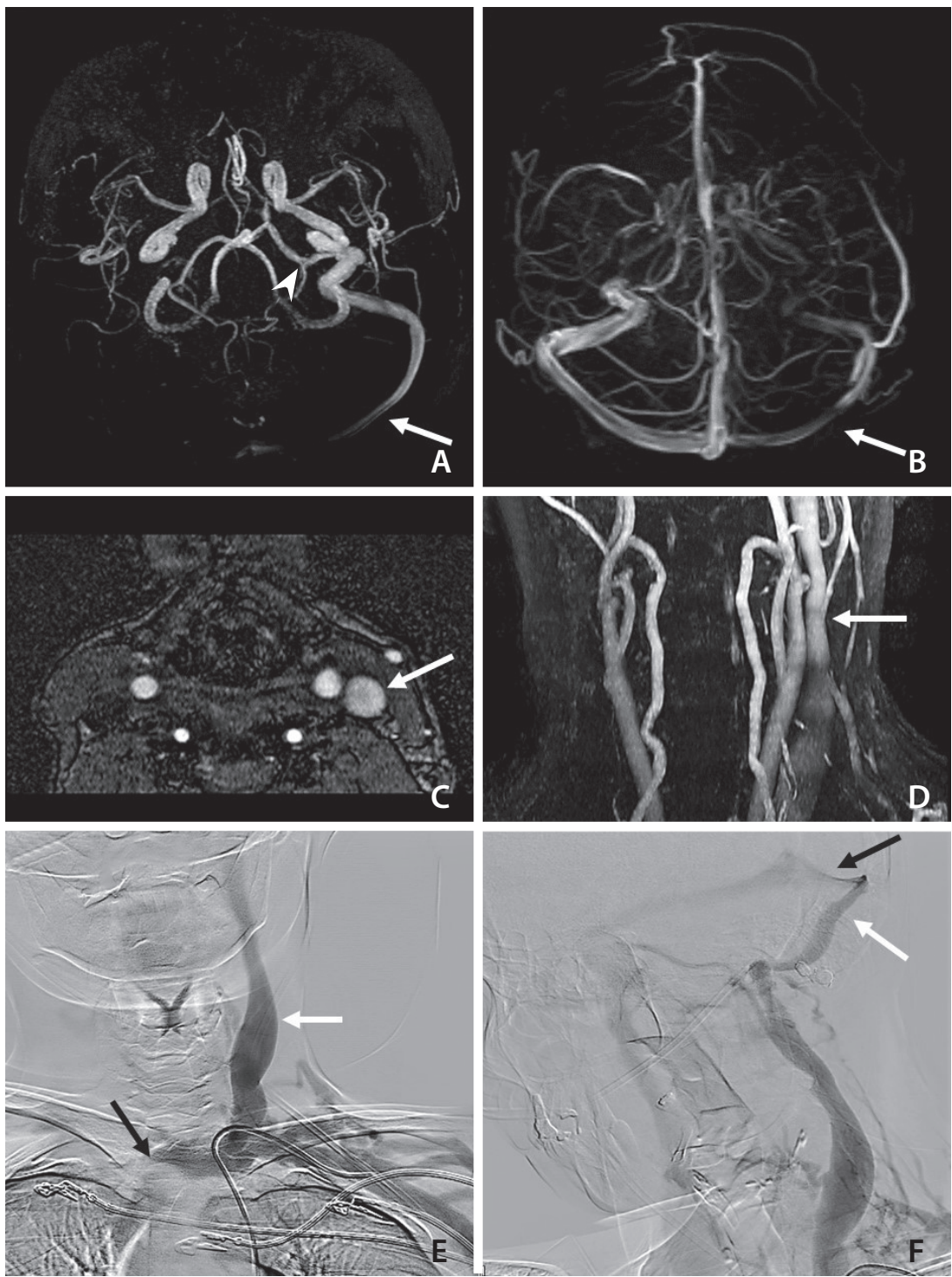

Fig. 1. (A) Brain time-of-flight (TOF) magnetic resonance angiography (MRA) shows reflux venous flow in the sigmoid sinus, transverse sinus (white arrow), and inferior petrosal sinus (arrowhead) on the left side. (B) Brain TOF magnetic resonance venography shows reflux venous signals in the left transverse sinus (white arrow). (C, D) Neck TOF MRA demonstrates retrograde flow in the left internal jugular vein (IJV) (white arrow). (E) Digital subtraction angiography (DSA) after injection in the left brachial artery shows reflux venous flow in the left IJV (white arrow) and incomplete thrombosis of the left brachiocephalic vein (black arrow). (F) Delayed venous phase images of DSA show retrograde flow in the IJV, sigmoid sinus (white arrow), and transverse sinus (black arrow) on the left side. 


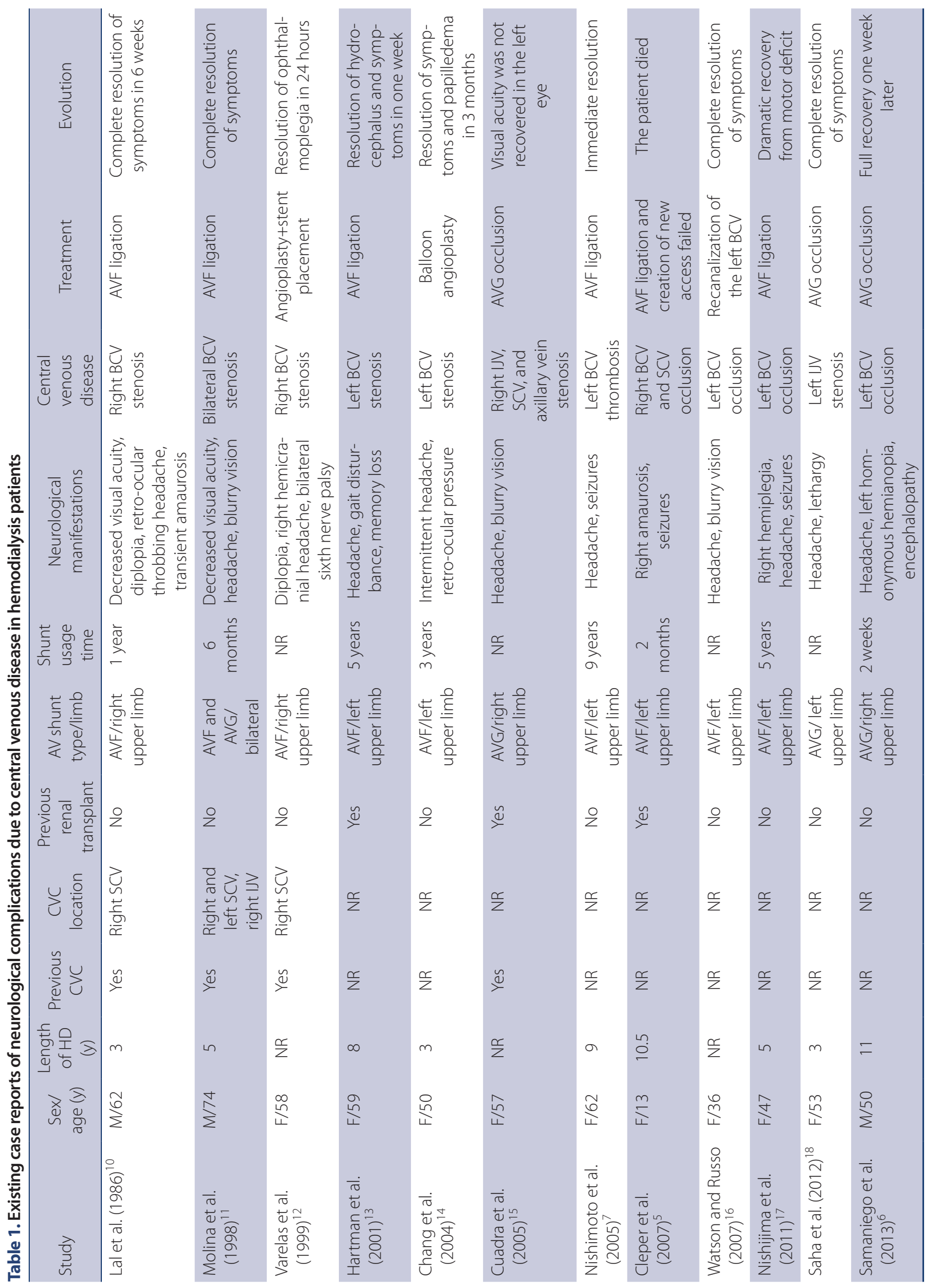




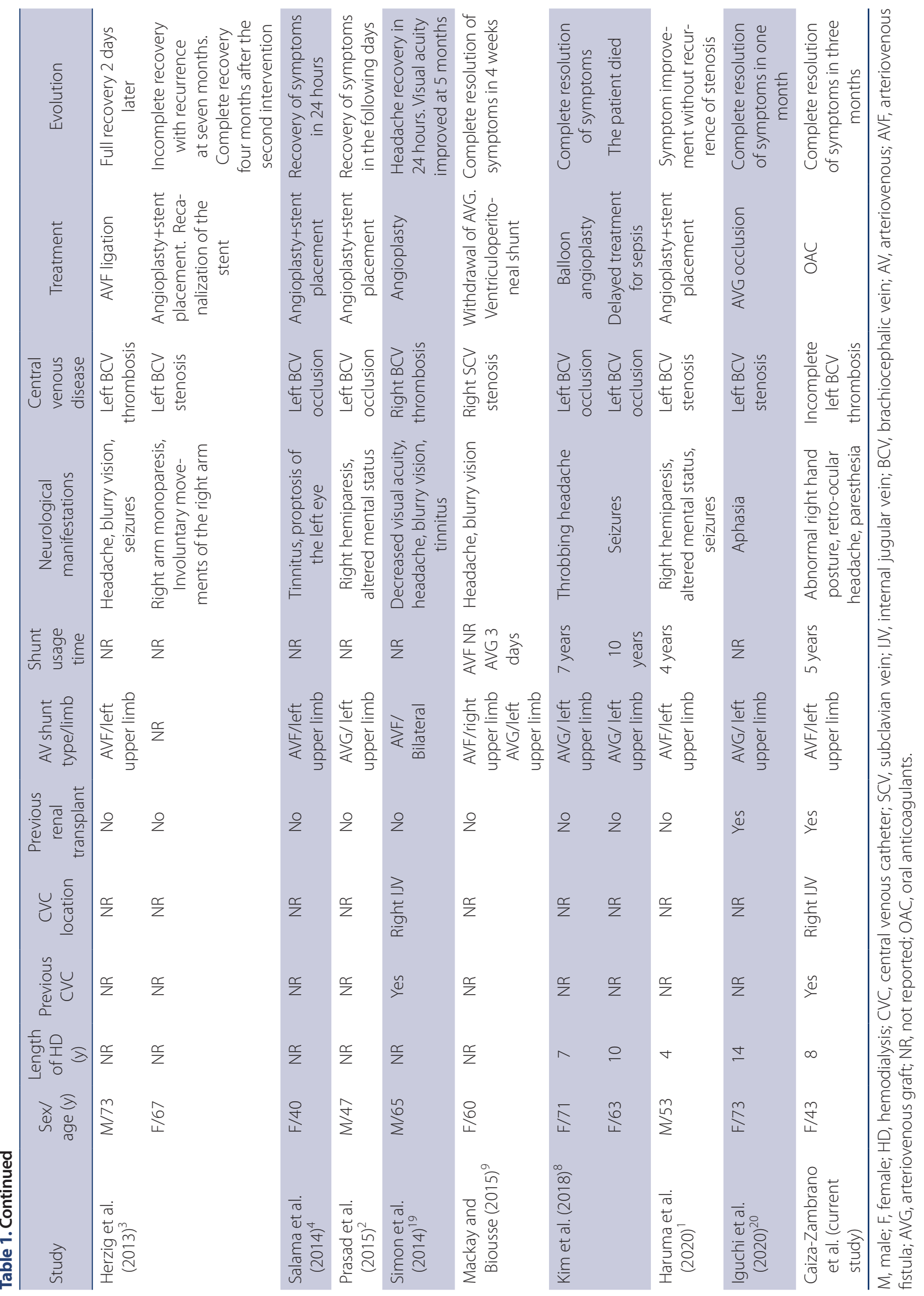


only if there is a clinical indication (arm or face swelling). ${ }^{4}$ Balloon dilation for a narrow lesion found incidentally without symptoms accelerates the growth of the lesion. All the current treatment options will lead to recurrent stenosis or occlusion requiring multiple repeat interventions to maintain patency, but the risk of vessel rupture may increase. ${ }^{2}$

Other options may be decongestion of the cerebral venous system by closing the active vascular access, but an alternative vascular access should be insured to continue renal replacement therapy. ${ }^{6,11}$ Ligation/occlusion was performed in half of the reported patients, and less frequently (39.1\%) when they underwent PTA. Twenty patients had good outcomes with a disappearance or clear improvement of symptoms after treatment.

Due to the location and type of lesion, our patient was not eligible for endovascular treatment. AVF ligation was not possible because the patient did not have another adequate venous access for a new AVF placement. Our patient represents the first reported case of neurologic manifestations secondary to CVD with complete resolution of symptoms after oral anticoagulants therapy. We have no evidence about medical therapy for secondary prevention for CVD. Further randomized controlled trials of currently available treatment options with long-term follow-up are essential in the future to develop adequate treatment algorithms.

Central venous reflux due to CVD is a serious complication in patients undergoing hemodialysis. Neurological manifestations are infrequent; therefore, this entity requires a high index of suspicion in those patients under hemodialysis who present neurological symptoms. Moreover, anticoagulation could be considered as an alternative treatment in special cases.

\section{Fund}

None.

\section{Ethics Statement}

This case report was approved by the Institutional Review Board (British Hospital Institutional Bioethics Committee) and conducted according to the criteria set by the declaration of Helsinki. Written informed consent for publication of her details was obtained from the patient.

\section{Conflicts of Interest}

The authors have no conflicts to disclose.

\section{Author Contributions}

Concept and design: FCZ, CMP, SG, and PB. Analysis and interpretation: FMG, MBB, MF, and MS. Data collection: FMG, $M B B, F L, M F$, and MS. Writing the article: FCZ, CMP, SG, and $P B$. Critical revision of the article: $S G, C R, R R$, and MFP. Final approval of the article: CR, RR, MFP, and PB. Statistical analysis: FL and MF.

\section{ORCID}

Francisco Caiza-Zambrano: https://orcid.org/0000-00016902-1545

Carolina Mora Palacio: https://orcid.org/0000-0002-0376-3527

Silvia Garbugino: https://orcid.org/0000-0002-1755-1461

Fabio Maximiliano Gonzalez: https://orcid.org/0000-00026217-3332

Marta Bala Biolcati: https://orcid.org/0000-0001-9950-2606

Miguel Ángel Saucedo: https://orcid.org/0000-0003-4496-5990

Carlos Rugilo: https://orcid.org/0000-0001-9822-7956

Mariano Forrester: https://orcid.org/0000-0002-8172-9586

Fernando Lombi: https://orcid.org/0000-0002-5873-9364

Manuel Fernández Pardal: https://orcid.org/0000-0002-2908-5189

Ricardo Reisin: https://orcid.org/0000-0002-7278-4639

Pablo Bonardo: https://orcid.org/0000-0002-9778-5128

\section{REFERENCES}

1. Haruma J, Escalard S, Smajda S, Piotin M. Left temporal hemorrhage caused by cerebral venous reflux of a brachio-brachial hemodialysis fistula. Neuroradiology 2020;62:1341-1344

2. Prasad V, Baghai S, Gandhi D, Moeslein F, Jindal G. Cerebral infarction due to central vein occlusion in a hemodialysis patient. J Neuroimaging 2015;25:494-496

3. Herzig DW, Stemer AB, Bell RS, Liu AH, Armonda RA, Bank WO. Neurological sequelae from brachiocephalic vein stenosis. J Neurosurg 2013;118:1058-1062

4. Salama GR, Farinhas JM, Pasquale DD, Wertenbaker C, Bello JA. Central venous occlusion mimics carotid cavernous fistula: a case report and review of the literature. Clin Imaging 2014;38:884-887

5. Cleper R, Goldenberg-Cohen N, Kornreich L, Krause I, Davidovits M. Neurologic and ophthalmologic complications of vascular access in a hemodialysis patient. Pediatr Nephrol 2007;22:13771382

6. Samaniego EA, Abrams KJ, Dabus G, Starr R, Linfante I. Severe venous congestive encephalopathy secondary to a dialysis ar- 
teriovenous graft. J Neurointerv Surg 2013;5:e37

7. Nishimoto H, Ogasawara K, Miura K, Ohmama S, Kashimura H, Ogawa A. Acute intracranial hypertension due to occlusion of the brachiocephalic vein in a patient undergoing hemodialysis. Cerebrovasc Dis 2005;20:207-208

8. Kim $\mathrm{CH}$, Kang J, Choi DS, Park JH. Intracranial venous reflux caused by occlusion of the brachiocephalic vein mimicking dural arteriovenous fistula. World Neurosurg 2018;120:438-441

9. Mackay DD, Biousse V. Hemodialysis graft-induced intracranial hypertension. Neurol Clin Pract 2015;5:494-497

10. Lal SM, Twardowski ZJ, Van Stone J, Keniston D, Scott WJ, Berg $\mathrm{GG}$, et al. Benign intracranial hypertension: a complication of subclavian vein catheterization and arteriovenous fistula. Am J Kidney Dis 1986;8:262-264

11. Molina JC, Martinez-Vea A, Riu S, Callizo J, Barbod A, Garcia C, et al. Pseudotumor cerebri: an unusual complication of brachiocephalic vein thrombosis associated with hemodialysis catheters. Am J Kidney Dis 1998;31:E3

12. Varelas PN, Bertorini TE, Halford H. Bilateral ophthalmoplegia and exophthalmos complicating central hemodialysis catheter placement. Am J Kidney Dis 1999;33:966-969

13. Hartmann A, Mast H, Stapf C, Koch HC, Marx P. Peripheral hemodialysis shunt with intracranial venous congestion. Stroke 2001;32:2945-2946
14. Chang S, Masaryk TJ, Lee MS. Optic nerve edema: complication of peripheral hemodialysis shunt. Semin Ophthalmol 2004;19:88-90

15. Cuadra SA, Padberg FT, Turbin RE, Farkas J, Frohman LP. Cerebral venous hypertension and blindness: a reversible complication. J Vasc Surg 2005;42:792-795

16. Watson RR, Russo C. Upper extremity arteriovenous dialysis fistula resulting in cavernous sinus arterialized blood flow. AJNR Am J Neuroradiol 2007;28:1155-1156

17. Nishijima H, Tomiyama M, Haga R, Ueno T, Miki Y, Arai A, et al. Venous cerebral infarction in a patient with peripheral hemodialysis shunt and occlusion of the left brachiocephalic vein. $J$ Stroke Cerebrovasc Dis 2011;20:381-383

18. Saha MK, Hamieh T, Larkin B, Mcmillan W. Cerebral hemorrhage due to internal jugular vein stenosis in a hemodialysis patient. Clin Exp Nephrol 2012;16:345-349

19. Simon MA, Duffis EJ, Curi MA, Turbin RE, Prestigiacomo CJ, Frohman LP. Papilledema due to a permanent catheter for renal dialysis and an arteriovenous fistula: a "two hit" hypothesis. J Neuroophthalmol 2014;34:29-33

20. Iguchi T, Harada M, Kurihara S, Ichikawa T, Satoh S, Kobayashi M. Neurological symptoms due to intracranial venous congestion in a hemodialysis patient with arteriovenous shunted flow. Kidney Int Rep 2020;5:2097-2101 